\title{
Echocardiography may help detect pulmonary vasculopathy in the early stages of pulmonary artery hypertension associated with systemic sclerosis
}

\author{
Walter Serra*1, Alfredo Chetta², Daniele Santilli3, Flavio Mozzani³, Pier Paolo Dall'Aglio33, Dario Olivieri², \\ Maria Alberta Cattabiani ${ }^{1}$, Diego Ardissino ${ }^{1}$ and Tiziano Gherli ${ }^{1}$
}

\begin{abstract}
Background: Pulmonary arterial hypertension (PAH) in patients with systemic sclerosis is associated with a poor prognosis, but this can be improved by early disease detection. Abnormal pulmonary and cardiac function can be detected early by means of echocardiography, whereas right heart catheterization is usually performed later.

Objectives: The purpose of this prospective study was to detect early the presence of pulmonary artery vasculopathy in patients with verified systemic sclerosis without significant pulmonary fibrosis, normal lung volumes and a mildly reduced lung diffusion capacity of carbon monoxide (DLCO).

Methods: Nineteen consecutive female NYHA class I-II patients with scleroderma and a PAPs of $<35 \mathrm{~mm} / \mathrm{Hg}$ measured by echocardiography, were enrolled between September 2007 and September 2009. They had a mean age of $51 \pm 13$ years, body mass index of $25 \pm 5 \mathrm{~kg} / \mathrm{m}^{2}$ ). They all underwent complete Doppler echocardiography, CPET, a pulmonary ventilation test (carbon monoxide lung diffusion, DLCO), HRCT. To investigate PAH by means of complete resting Doppler echocardiography estimates of systolic pulmonary artery pressure (PAPs) derived from tr icuspid regurgitation, mean PAP derived from pulmonary regurgitation, pulmonary vessel resistance (PVR) derived from the acceleration time of the pulmonary outflow tract (ACTpo), and right ventricular function derived from tricuspid annular plane systolic excursion (TAPSE). Right heart catheterisation was conducted only, if pulmonary hypertension was suggested by echocardiography and an abnormal ventilator test.

The data are given as mean values $\pm S D$, unless otherwise stated. The correlations between the variables were analysed using Pearson's $r$ coefficient, and the predictive value of the variables was calculated using linear regression analysis. A $p$ value of $>0.05$ was considered significant.
\end{abstract}

Results: Right heart catheterization detected PAH in 15/19 patients; mean PAP was $30.5 \mathrm{~mm} / \mathrm{Hg}$ and RVP 3.6 UW. Coronary angiography of the patients aged more than 55 years showed some evidence of significant coronary artery disease. Echocardiography showed high systolic PAP values $(46 \pm 8 \mathrm{mmHg})$, whereas right ventricular function was normal (TAPSE $23 \pm 3 \mathrm{~mm}$ ), and in line with the NYHA class. ACTpo was reduced in the patients with a systolic PAP of $<$ $46 \mathrm{~mm} / \mathrm{Hg}(p>0.001)$ and positively correlated with DLCO $(p>0.001)$ and the hemodynamic data.

There was a good correlation between ACTpo and PVR (hemodynamic data) ( $r=-0615 ; p>0.01$ ).

Conclusions: Although they need to be confirmed by studies of larger series of patients, our findings suggest that, in comparison with hemodynamic data, non-invasive echocardiographic measurements are an excellent means of identifying early-stage PAH.

\footnotetext{
* Correspondence: wserra@libero.it

1 Cardiopulmonary Dept., Cardiology Unit, University Hospital, Parma, Italy

Full list of author information is available at the end of the article
}

๑ 2010 Serra et al; licensee BioMed Central Ltd. This is an Open Access article distributed under the terms of the Creative Commons BH Ied Central Attribution License (http://creativecommons.org/licenses/by/2.0), which permits unrestricted use, distribution, and reproduction in any medium, provided the original work is properly cited. 


\section{Introduction}

Systemic sclerosis is a chronic disease essentially due to microvascular abnormalities, antibodies and a fibroblast production that leads to excessive collagen levels, and skin and viscera fibrosis[1-3].

The most recent data show that the prevalence of systemic sclerosis from 1977 to 1980 was 12.6-25/100,000, with an incidence of $0.06-1.9 / 100,000$. The recorded mean age of the patients at the time of onset is between 45 and 65 years, this data does not reflect the real age as the symptoms may appear many years before the first specialist assessment. The main pulmonary complications are pulmonary fibrosis and pulmonary arterial hypertension $(\mathrm{PAH})$ : interstitial lung disease is observed in $70 \%$ of the patients with diffused systemic sclerosis, and pulmonary hypertension in $35 \%$ of those with limited systemic sclerosis[4,5]. The patients have no symptoms at rest during the initial stages of the disease, but soon develop slight dyspnea during physical exercise or rest; some may also experience chest pain, asthenia and loss of conscience under stress.

As pulmonary hypertension in systemic sclerosis may not only be due to $\mathrm{PAH}$, but also to interstitial lung disease and cardiac involvement[6-9], it is very important to classify it adequately[10,11] in order to determine the best treatment. According to the 2009 guidelines[12], PAH describes an increase in mean pulmony artery pressure (PAPm) to more than $25 \mathrm{mmHg}$. Echocardiography and respiratory function testing are recommended every year, even if the patient is asymptomatic, and right heart catheterisation is usually performed in late stages.

The published frequencies of PAH in systemic sclerosis vary widely (from $5 \%$ to $35 \%$ ), depending on the study population, and diagnostic methods (cardiac echo-Doppler or right heart catheterisation) and criteria. Echocardiography plays a central role in the non-invasive screening and management of patients with suspected $\mathrm{PAH}$ as it guarantees the early identification and treatment of a condition that is usually diagnosed at least two or three years after its onset[13-15].

PAH and interstitial lung disease are the leading causes of death in systemic sclerosis and, as their early detection and treatment should improve morbidity and mortality $[16,17]$. The aim of this prospective study was to detect the presence of pulmonary artery vasculopathy early in patients with verified systemic sclerosis and normal lung volumes, no significant pulmonary fibrosis, and mildly reduced lung carbon monoxide diffusing capacity (DLCO) by: 1) evaluating resting pulmonary function at rest, and maximum and sub-maximum exercise capacity; 2) detecting systolic pulmonary artery pressure (PAPs) values of $<35 \mathrm{mmHg}$ using thoracic echocardiography; and 3) investigating the relationships between PAP and the acceleration time of the pulmonary outflow tract (ACTpo), right ventricular function (tricuspid annular plane systolic excursion; TAPSE), and right heart catheterisation (PAPs, PAPm and pulmonary vessel resistance [PVR]).

\section{Patients and Methods}

19 female patients, aged between 28 and 75 (51 \pm 13$)$; BMI $(\mathrm{Kg} / \mathrm{m} 2) 25 \pm 5$, NYHA class $\mathrm{I}^{\wedge}-\mathrm{II}^{\wedge}$ diagnosed with Systemic Sclerosis were enrolled between 2007 and 2009 in collaboration with the Rheumatic Department of the University Hospital of Parma (EULAR Scleroderma Trials criteria)[18].

All patients had standard pulmonary function tests, including FVC and DLCO; auto-antibodies (ANA) including anti-centromere, anti-Scl-70 were performed as available from commercial laboratories.

A chest radiograph and a high resolution $\mathrm{CT}$ scan (HCRT) were performed to select patients without significant pulmonary fibrosis.

Patients without significant pulmonary fibrosis with reduced lung volumes, left heart dysfunction and significant valvular disease were enrolled. [see Additional file 1]

ECG: rhythm, heart rate and strain in the right ventricle

\section{Doppler echocardiography}

The investigated echocardiographic parameters were PAPs (derived from a tricuspid regurgitation flow value of $<2.8 \mathrm{~m} / \mathrm{s}$ ), ACTpo (normal value $<130 \mathrm{msc}$ ), PVR (using the equation: PVR $=$ TRV/TVI rvot $\times 10+0.16$ )[19], inferior vena cava flow, diameter and inspiratory changes (normal value $>18 \mathrm{~mm}$ with respiratory collapse $<50 \%$ ), and Doppler tissue imaging (DTI) of the tricuspid annulus, which were evaluated using a Phillips IE33 echocardiograph equipped with 2.5 and $3.5 \mathrm{MHz}$ electronic transducers, harmonic imaging and DTI.

\section{Respiratory function}

Respiratory function was tested in accordance with international recommendations using a pneumotachograph and plethysmographic cabin connected to a computer for data analysis (Vmax 22 and 6200, Sensor Medics, Yorba Linda, CA)[20,21].

The analysed parameters were total lung capacity (TLC), volume residue (VR), forced expiratory volume in one second $\left(\mathrm{FEV}_{1}\right)$, and the $\mathrm{FEV}_{1} / \mathrm{FVC}$ ratio. DLCO was calculated using the single breath method, and the test was only considered valid when the inspiratory volume was the same as at least $90 \%$ of FVC. Each variable was measured at least three times. The theoretical lung volume and DLCO values were obtained using the Quanjer and Cotes regression equations[22]. 


\section{Six-minute walking test}

The six-minute walking test (6MWT) consists of walking along a 30-metre corridor for the longest distance possible in six minutes using a standard protocol; as the test is symptom-limited, the patients are allowed to stop and resume walking when they wish. Before and after the test, the patients' vital parameters were recorded and the patients complete a visual analogue scale (VAS) quantifying the degree of dispnea. Oxygen saturation $\left(\mathrm{SPO}_{2}\right.$, expressed as a percentage) and heart rate (HR, expressed as beats per minute $[\mathrm{bpm}]$ ) were continuously monitored and recorded every 10 seconds from five minutes before the walk to five minutes after returning to baseline values using a portable pulsometer (Model $920 \mathrm{M}$, Healthdyne, Marietta, GA). To allow for the learning effect, a pause of 60 minutes was allowed between each test.

\section{Cardiopulmonary exercise test}

A cardiopulmonary exercise test CPET) was performed following a standardised procedure (ATS/ACCP Statement, 2003)[23]. After the oxygen and carbon dioxide analysers and the flow mass sensor had been calibrated, the study patients were asked to sit on an electromagnetically braked cycle ergometer (Corival PB, Lobe BV, Groningen, The Netherlands) for a 3-minute rest period, with the saddle adjusted to avoid maximum extension of the knee. Exercising began with a 3-minute warm-up period at 0 watts, followed by a progressively increasing ramp protocol of 5-15 watts/min (depending on the anthropometric data and the patients' degree of functional impairment) for a period of 8-12 minutes. The patients were required to maintain a pedalling frequency of $60 \mathrm{rpm}$, as indicated by a digital display on the monitor of the ergometer.

During the test, breath-by-breath $\mathrm{VO}_{2}(\mathrm{~mL} / \mathrm{min})$, carbon dioxide production $\left(\mathrm{VCO}_{2}, \mathrm{~mL} / \mathrm{min}\right)$ and minute ventilation (VE, $\mathrm{L} / \mathrm{min}$ ) were collected (Vmax 229, Sensor Medics, Yorba Linda, CA), the patients were continuously monitored by means of a 12-lead electrocardiogram (Corina, GE Medical Systems IT Inc., Milwaukee, WI) and pulse oximeter (Pulse Oximeter 8600, Nonin Medical Inc., $\mathrm{MN}$ ), and blood pressure was measured at two-minute intervals. Resting end-tidal $\mathrm{CO}_{2}$ pressure (rest $\mathrm{PETCO}_{2}, \mathrm{~mm} \mathrm{Hg}$ ) was recorded as the mean value measured during the 3-minute rest period, and peak $\mathrm{VO}_{2}$ as the mean value during the last 20 seconds of the test (expressed in $\mathrm{mL} / \mathrm{min}$ and $\mathrm{mL} / \mathrm{kg} / \mathrm{min}$ ). Ventilatory response to exercise was calculated as a linear regression function by plotting $\mathrm{VE}$ against $\mathrm{VCO}_{2}$ every 10 seconds of exercise ( $\mathrm{VE} / \mathrm{VCO}_{2}$ slope).

\section{Right heart catheterisation}

The patients aged more than 55 years underwent femoral right heart catheterisation using a 7F catheter thermo dilution, to evaluate systolic, mean and capillary pulmonary pressure and calculate the trans-pulmonary gradient $(\mathrm{GTP}=\mathrm{PAPm} / \mathrm{CO}), \mathrm{PVR}($ dynes.scm $-5=\mathrm{GTP} / \mathrm{CO} \times 80)$ and cardiac output (CO). PAH was defined as a PAPm of $<25 \mathrm{~mm} / \mathrm{Hg}$ and Pulmonary Capillary Wedge Pressure (PCWP) of $>15 \mathrm{~mm} / \mathrm{Hg}$. Measuring the pressure of the pulmonary occlusion makes it possible to identify the pulmonary pressure site and allows the diagnosis of the pulmonary hypertension site (pre-/post-capillary).

\section{Statistical analysis}

The primary objectives were to assess the associations between $\mathrm{DLCO} \%$ at rest and PAP, and between the echocardiographic and right heart catheterisation measurements of PVR. All of the data are given as mean values \pm SD unless otherwise stated. Pearson's correlation coefficient and Bland-Altman analysis were used to compare PAPs, ACTpo and TAPSE with DLCO, VO2max\%, VE/VCO2, O2 pulse, NYHA class and PVR. Stepwise forward multiple regression analysis allowed the weighting of the independent effects of the potential determinants on an independent variable. The null hypothesis was rejected when $\mathrm{p}$ was $>0.05$.

ACTpo was measured by two echocardiographers blinded to the clinical data in order to assess interobserver variability.

\section{Results}

Seventeen of the 19 patients had limited cutaneous systemic sclerosis, and two an overlap syndrome including scleroderma.

\section{Pulmonary function data}

The patients were selected because the results of respiratory function testing at rest (FVC/DLCO) aroused a suspicion of pulmonary vasculopathy (Tab 1). Flow, volume were normal, but not DLCO (71\% of the theoretical value) and FV/DLCO (1.5). The distance covered in the 6 MWT was normal $(424 \pm 102 \mathrm{~m}$ ) (Tab 2). During the cardiopulmonary test, there was a moderate reduction in exercise capacity (VO2max\% theoretical $68 \pm 14 \%$ ), a reduction in oxygen pulse $(8.1 \pm 1.7 \mathrm{ml} /$ beat $)$, and a reduction in the equivalent $\mathrm{CO} 2$ ventilators $(\mathrm{VE} / \mathrm{VCO} 2$ slope $38 \pm 12$ ) (Tab 3 ).

\section{Echocardiography}

Systolic pulmonary pressure was high $(46 \pm 8 \mathrm{mmHg})$, but right ventricular function was normal (TAPSE $23 \pm$ 3), and in line with the patients' NYHA class (Tab. 4).

In the patients with high PAPs, echocardiography showed a reduction in acceleration time on the pulmonary flow velocity curve (ACTpo $121 \mathrm{msc})(\mathrm{p}>0.001)$ that corresponded with the diffusion capacity at rest (DLCO\%). 
Table 1: The functional respiratory values at rest (flow, volume, MIP and MEP) were normal except DLCO $(71 \% \pm$ theoretical) and FV/DLCO $(1,5)$

\begin{tabular}{ll}
\hline DATA & Mean \pm SD \\
\hline Age $(y \pm)$ & $54 \pm 11$ \\
\hline BMI $\left(\mathrm{Kg} / \mathrm{m}^{2}\right)$ & $25 \pm 5$ \\
\hline $\mathrm{FEV}_{1}(\mathrm{~L})$ & $2,47 \pm 0,60$ \\
\hline $\mathrm{FEV}{ }_{1}(\%$ theoretical $)$ & $106 \pm 26$ \\
\hline $\mathrm{FEV} / \mathrm{SVC}$ (\%) & $81 \pm 3$ \\
\hline TLC (\% theoretical) & $97 \pm 20$ \\
\hline FVC (\% theoretical) & $102 \pm 18$ \\
\hline DLCO (\% theoretical) & $71 \pm 18$ \\
\hline FVC/DLCO & $1,5 \pm 0,4$ \\
\hline
\end{tabular}

Mean ACTpo and PVR were respectively $117 \mathrm{msc}$ and $3.31 \mathrm{UW}$.

There was a significant correlation between PAPs and NYHA class $(r=069 ; p>0.05)$, between TAPSE and NYHA class $(r=-0.47 ; p>0.05)$, and between DLCO and peak VO2 $(\mathrm{p}>0.05)$, and a good correlation between ACTpo and NYHA class $(r=-0.71 ; p>0.001)$. [see Additional file 2]

\section{Right heart catheterisation}

Right heart catheterisation detected PAH in 15/19 patients, and one patient had veno-occlusive pulmonary hypertension; PAPm was $30.5 \mathrm{mmHg}$ and PVR $3.6 \mathrm{UW}$.

Table 2: The 6MWT showed a normal range test (424 +-102 m)

\begin{tabular}{ll}
\hline Parameter & Mean \pm SD \\
\hline Distance (meter) & $424 \pm 102$ \\
\hline Distance(\% theoretical) & $122 \pm 12$ \\
\hline $\begin{array}{l}\text { Oxigen Hemoglobinic } \\
\text { Desaturation (\%) }\end{array}$ & $2 \pm 3$ \\
\hline
\end{tabular}

Table 3: CPET showed: VO2 max \% theoretical (68 \pm 14$)$, a reduction in the oxygen pulse $(8,1 \pm 1,7)$ and the equivalent $\mathrm{CO} 2$ ventilators (VE/VCO2 slope $38 \pm 12$ )

\begin{tabular}{|c|c|}
\hline Parameter & Mean \pm SD \\
\hline $\mathrm{V}^{\prime} \mathrm{O}_{2} \max (\mathrm{ml} / \mathrm{kg} / \mathrm{min})$ & $19,9 \pm 7,1$ \\
\hline $\mathrm{V}^{\prime} \mathrm{O}_{2} \max (\mathrm{L} / \mathrm{min})$ & $1,18 \pm 0,34$ \\
\hline $\mathrm{V}^{\prime} \mathrm{O}_{2} \max (\%$ theoretical) & $63 \pm 14$ \\
\hline V'O ${ }_{2} @ A T(I / m i n)$ & $0,90 \pm 0,26$ \\
\hline 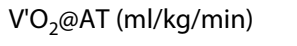 & $14,6 \pm 5,5$ \\
\hline Watts & $75 \pm 34$ \\
\hline (\% theoretical) & $77 \pm 20$ \\
\hline $\mathrm{V}^{\prime} \mathrm{O}_{2} /$ Watts & $7,2 \pm 2,7$ \\
\hline HR max (bmp) & $146 \pm 24$ \\
\hline HR (\%) & $88 \pm 13$ \\
\hline $\mathrm{O}_{2 \text { pulse }}(\mathrm{ml} / \mathrm{bpm})$ & $8,1 \pm 1,7$ \\
\hline $\mathrm{HR} / \mathrm{VO}_{2}$ & $66 \pm 20$ \\
\hline VE max (\%) & $50 \pm 20$ \\
\hline VE/VCO 2 (slope) & $38 \pm 12$ \\
\hline
\end{tabular}

There was a good correlation between ACTpo and PVR $(\mathrm{r}=-0615 ; \mathrm{p}>0.01)($ Fig 1$)$.

Coronary angiography (carried out in the patients aged $<55$ years) did not reveal any signs of significant coronary artery disease.

\section{Discussion}

Pulmonary artery hypertension is the most frequent cause of death in scleroderma patients, and its early identification is the best means of improving survival.

By allowing a non-invasive evaluation of the right atrium ventricular gradient, post-systolic tricuspid annular movement (TAPSE) and the acceleration time of right outflow (ACTpo, an indirect marker of pulmonary vascular resistance), echocardiography reveals the presence of pulmonary hypertension even in patients in a less 
Table 4: Echo data showed high pulmonary systolic pressure values $(46 \pm 8 \mathrm{mmHg})$, while the right ventricular function was normal (TAPSE $23 \pm 3$ )

\begin{tabular}{ll}
\hline Parameter & Mean \pm SD \\
\hline NYHA (I-IV) & $I I(I-I I)^{*}$ \\
\hline PAPs $(\mathrm{mm} \mathrm{Hg})$ & $46 \pm 8$ \\
\hline TAPSE $(\mathrm{mm})$ & $23 \pm 3$ \\
\hline ACTpo $(\mathrm{msec})$ & $117 \pm 6$ \\
\hline PVR $(\mathrm{WU})$ & $3.31 \pm 2$ \\
\hline
\end{tabular}

advanced functional class. The data obtained by means of invasive right heart catheterisation confirmed our echocardiographic findings, which overestimated three cases with tricuspid gradient values of $>3 \mathrm{~m} / \mathrm{sec}$ [24-26].

Echocardiographic measurements of the tricuspid gradient are accurate but may lead to overestimated pulmonary pressures or, less frequently, underestimates due to an incorrectly aligned regurgitated jet. Valchiery et al. found a good correlation between invasive and non-invasive (echocardiographic) measurements of PAPs $(r=0.57$, $\mathrm{p}>0.001$ ), but other authors have found discrepancies in $35 \%$ of cases[27]. The discrepancies are possibly due to factors such as inexperience with the technique, an incorrectly aligned regurgitated jet (which can be better defined using contrast medium), or incorrect right atria pressure, which can be better evaluated using the diameter and the collapse of the inferior vena cava during a breath in.

According to the 2009 guidelines[12], PAH should not be diagnosed by means of echocardiography alone. However, as it detected pulmonary vasculopathy early on the

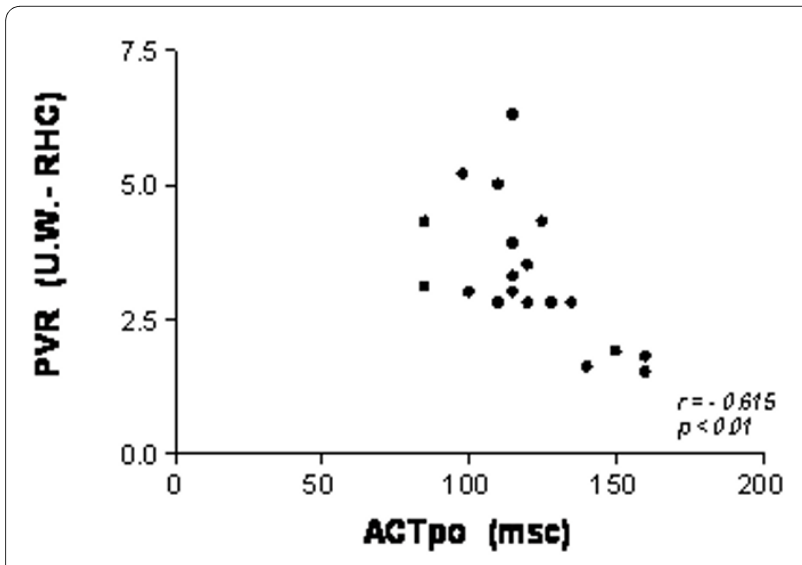

Figure 1 Correlation between ACTpo and PVR (RHC). basis of the ACTpo, TAPSE and PAPs findings, we believe that the echocardiographic estimate of PVR should become a part of a standard examination. Three-dimensional echocardiography or cardiac magnetic resonance may be useful in evaluating right ventricular function, but neither were used in this study.

Echocardiography and CPET are both essential for screening patients at risk of developing $\mathrm{PAH}$, which in any case needs to be confirmed by catheterisation, which also provides prognostic data that are useful for therapeutic purpose[26-29].

\section{Conclusions}

The alterations in cardiorespiratory function described above represent initial signs of pulmonary and cardiac vessel impairment in patients with systemic sclerosis. Echocardiographic findings non-invasively reveal the presence of increased pulmonary pressure and pulmonary vascular resistance, morphological changes, and functional abnormalities in right ventricular parameters, which cannot be identified by means of catheterisation. The early recognition of vascular involvement together with a multidisciplinary approach to the illness should lead to better therapeutic results[30,31].

\section{Study limitations}

The main limitation of this study is the small number of patients, and so the findings need to be confirmed in larger series. Misalignment due to the equalisation of pressure between the right atrium and ventricle may lead to underestimated echocardiographic calculations of PAPs and PVR, but we found a good level of interobserver agreement concerning tricuspid regurgitation velocity and pulmonary outflow acceleration time ( $\mathrm{p}>$ $0.5)$.

\section{Consent}

All patients provided written informed consent to participate in the research

\section{Additional material}

Additional file 1 Patient's data. Seventeen of the 19 patients had limited cutaneous systemic sclerosis, and two an overlap syndrome including scleroderma.

Additional file $\mathbf{2}$ ECHO an RHC data. There was a significant correlation between TAPSE and NYHA class $(r=-0.47 ; p>0.05)$ and a good correlation between ACTpo and NYHA class ( $r=-0.71 ; p>0.001)$. Right heart catheterisation detected PAH in 15/19 patients: PAPm was $30.5 \mathrm{mmHg}$ and PVR 3.6 UW.

\section{Abbreviations}

ACTPO: Pulmonary outflow acceleration time; BR: Breath reserve (MVV-VEmax); CO: Cardiac Output; CPET: Cardio Pulmonary Exercise Test; DLCO: Carbon monoxide lung diffusion.; $\mathrm{FEV}_{1}$ : Forced expiratory volume in 1 second; FVC: Forced vital capacity; GTP: Transpulmonary gradient (PAPm/CO); MVV: Maximum Voluntary Ventilation; NYHA: New York Heart Association; ${ }_{2}$ Pulse: Oxygen Pulse 
(VO2/HR); PAH: Pulmonary Arterial Hypertension; PAPm: Pulmonary Artery Pressure mean; PCWP: Pulmonary Capillary Wedge Pressure; PVR: Pulmonary Vessel Resistance; RV: Residual Volume; SS: Systemic Sclerosis; TAPSE: Tricuspid annular plane systolic excursion; TLC: Total Lung Capacity; VAS: -Visual analogic Scale; VO2: Oxygen Consumption; VCO2: Carbon Dioxide production; VE/NCO2 slope: $\mathrm{CO} 2$ Ventilatory equivalent slope; VE/NO2 slope: O2 Ventilatory equivalent slope; 6MWT: 6 Minute Walking Test.

\section{Competing interests}

The authors declare that they have no competing interests.

\section{Authors' contributions}

WS conceived and carried out the study and drafted the manuscript. AC participated in the design of the study and performed the statistical analysis. DS, FM and PPDA contributed sending some scleroderma patients, essential for the study. MAC performed right heart catheterisation. DO, DA and TG participated in its design and coordination.

All authors read and approved the final manuscript.

\section{Acknowledgements}

Gianni Buticchi Rheumatology Unit, University Hospital, Parma, Italy, who contributed by sending some scleroderma patients, essential for the study. Claudio Reverberi Cardio-pulmonary Dept University Hospital, Parma, Italy, who contributed with instrumental equipment and materials essential for the study.

\section{Author Details}

${ }^{1}$ Cardiopulmonary Dept., Cardiology Unit, University Hospital, Parma, Italy, ${ }^{2}$ Cardiopulmonary Dept., Pneumology Unit, University Hospital, Parma, Italy and ${ }^{3}$ Immunology Dept., Rheumatology Unit, University Hospital, Parma, Italy

Received: 4 March 2010 Accepted: 5 July 2010

Published: 5 July 2010

\section{References}

1. Maddison PJ, Stephens C, Briggs D, et al:: "Connective tissue disease and autoantibodies in the kindreds $\mathrm{f} 63$ patients with systemic sclerosis". Medicine (Baltimore) 1993, 72:103.

2. Masi AT, D' Angelo WA: "Epidemiology of fatal systemic sclerosis (diffuse scleroderma): A 15-year survey in Baltimore". Ann Intern Med 1967, 66:870.

3. Hachulla E, Gressin V, Guillevin L, et al:: "L'Hypertension arterielle pulmonaire associée a la sclerodermie systemique: proposition d' un algorithme echocardiographique de dépistage pour un diagnostic précoce (ItinérAIR-Sclérodermie)". Rev Méd Interne 2004, 25:340-347.

4. Silver RM, Miller KS, Kinsella MB, et al.: " Evaluation and management of scleroderma lung disease using bronchoalveolar lavage". Am J Med 1990, 88:470.

5. Rubin LJ: "Primary pulmonary hypertension". N Engl J Med 1997, 336:111-117.

6. Runo JR, Loyd JE: "Primary pulmonary hypertension". Lancet 2003, 361:1533-1544

7. Barst RJ: "Medical therapy of pulmonary hypertension: an overview of treatment and goals". Clin Chest Med 2001, 22:509-515.

8. Simonneau G, Galie N, Rubin LJ, et al:: "Clinical classification of pulmonary hypertension". J Am Coll Cardiol 2004, 43(Suppl S):5S-12S.

9. Humbert M, Nunes H, Sitbon O, Parent F, Hervé P, Simonneau G: "Risk factors for pulmonary arterial hypertension". Clin Chest Med 2001, 22:459-475.

10. Farber HW, Loscalzo J: "Pulmonary Arterial Hypertension, mechanisms of disease". N Engl J Med 2004, 351(16):1655.

11. Simonneau G, Robbins I, Beghetti M, Channick RN, Decroix M, Denton CP, Elliott CG, Gaine S, Gladwin MT, Jing ZC, Krowka, et al:: Updated clinical classification of pulmonary hypertension. JACC 2009, 54:543-554

12. Galiè N, Hoeper M M, Humbert M, Torbicki A, Vachiery J L, Simonneau G, et al.: ESC-ERS-ISHLT Guidelines for the diagnosis and treatment of pulmonary hypertension. EHJ 2009.

13. Ungere RG, Tashking DP, Furst D, et al.: "Prevalence and clinical correlates of pulmonary arterial hypertension in progressive systemic sclerosis". Am J Med 1983, 75:65-74.
14. Murata I, Kihara H, Shinohara S, et al:: "Echocardiographic evaluation of pulmonary arterial hypertension in patients with progressive systemic sclerosis and related syndromes". Jpn Circ J 1992, 56:983-91.

15. Denton CP, Cailes JB, Phillips GD, et al:: "Comparison of Doppler echocardiography and right heart catheterization to assess pulmonary hypertension in systemic sclerosis". BRJ Rheumatol 1997, 36:239-43.

16. Koh ET, Lee P, Gladman DD, et al:: "Pulmonary hypertension in systemic sclerosis: an analysis of 17 patients". Br Rheumatol 1996, 35:989-93.

17. MacGregor AJ, Canavan R, Knight C, et al:: "Pulmonary hypertension in systemic sclerosis: risk factors for progression and consequences for survival". Rheumatology 2001, 40:453-9.

18. EULAR Scleroderma Trials And Research group database. Ann rheum Dis 2007, 66:754-763.

19. Abbas Amr E, et al:: A simple method for noninvasive estimation of pulmonary vascular resistance. JACC 2003, 41:1021-1027.

20. Miller MR, Hankinson J, Brusasco V, et al.: ATS/ERS Task Force. Standardization of spirometry. Eur Respir J 2005, 26:319-38.

21. Quanjer PhH, Tammeling GJ, Cotes JE: "Lung volumes and forced ventilatory flows". Eur Respir J 1993, 6:5-40.

22. Cotes JE, Chinn DJ, Quanjer PhH: "Standardization of the measurement of transfer factor (diffuse Capacity)". Eur Resp J 1993, 6:41-52.

23. ATS/ACCP Statement on cardiopulmonary exercise testing. Am J Respir Crit Care Med 2003, 167:211-77.

24. Pope JE, Lee P, Baron M, et al:: "Prevalence of elevated pulmonary arterial pressures measured by echocardiography in multicenter study of patients with systemic sclerosis". J Rheumato/ 2005, 32(7):1273-8.

25. Alkotob ML, Soltani P, Sheatt MA, et al:: "Reduced exercise capacity and stress-induced pulmonary hypertension in patients with sclerodermia". Chest 2006, 130:176-181.

26. Mukerjee D, St George D, Coleiro B, et al:: "Prevalence and outcome in systemic sclerosis associated pulmonary arterial hypertension: application of a registry approach". Ann Rheum Dis 2003, 62:1088-93.

27. Launay D, Hachulla E, Hantron PY, et al:: "Dèpistage de l'hypertension artérielle pulmonaire au cours de la sclérodermie systémique: étude d' une cohorte de 67 patients". Rev Méd Interne 2001, 22:819-29.

28. Hoeper MM: "Pulmonary hypertension in collagen vascular disease". Eur Respir J 2002, 19:5.

29. Mukerjee D, St George D, Knight C, et al:: "Echocardiography and pulmonary function as screening tests for pulmonary arterial hypertension in systemic sclerosis". Rheumatology 2004, 43:461-6.

30. Proudman M, Stevens WM, Sahharand J, Celermajer D: Pulmonary arterial hypertension in systemic sclerosis: the need for early detection and treatment. Internal Medicine Journal 2007, 37:485-49.

31. Subcommittee for Sclerodermia Criteria of the American Rheumatism Association Diagnostic and Therapeutic Criteria Committee. Preliminary criteria for the classification of systemic sclerosis (scleroderma). Arthritis Rheum 1980, 23:581-590.

doi: $10.1186 / 1476-7120-8-25$

Cite this article as: Serra et al., Echocardiography may help detect pulmonary vasculopathy in the early stages of pulmonary artery hypertension associated with systemic sclerosis Cardiovascular Ultrasound 2010, 8:25

\section{Submit your next manuscript to BioMed Centra and take full advantage of:}

- Convenient online submission

- Thorough peer review

- No space constraints or color figure charges

- Immediate publication on acceptance

- Inclusion in PubMed, CAS, Scopus and Google Scholar

- Research which is freely available for redistribution 